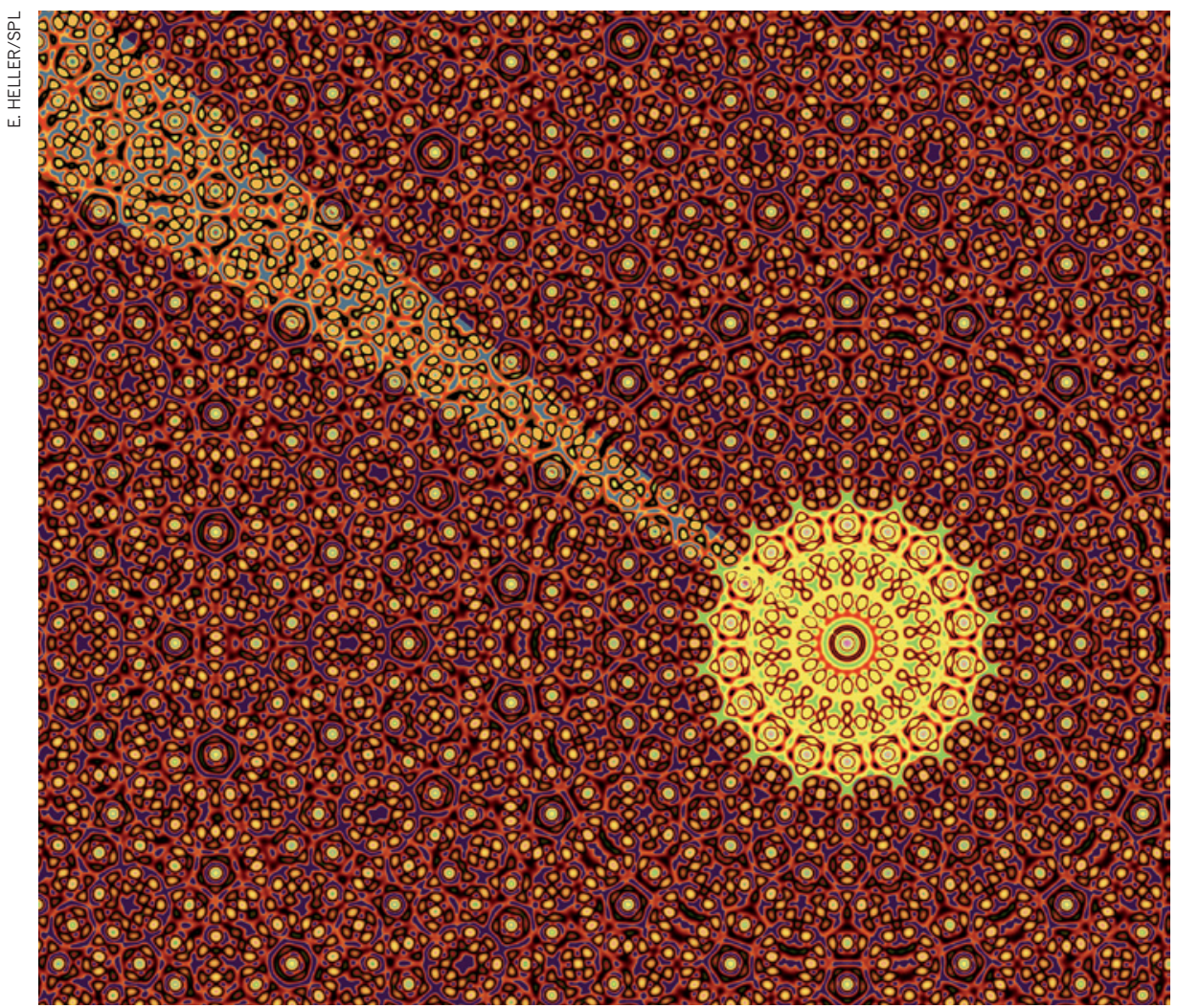

A quasicrystal's atomic structure never quite repeats itself, as shown in this computer simulation.

NOBEL PRIZE

\title{
Persistence pays off for crystal chemist
}

\section{Discovery of mosaic material wins Nobel prize.}

\section{BY RICHARD VAN NOORDEN}

A s Louis Pasteur famously pointed out: "In the fields of observation, chance favours only the prepared mind." Stumbling across a curiosity is not enough understanding it, and convincing the world of its importance, are key.

Dan Shechtman at the Technion Israel Institute of Technology in Haifa knows this only too well. Last week he was awarded the Nobel Prize in Chemistry for his 1982 observations of quasicrystals: materials with a mosaiclike atomic array that never quite repeats, thus flouting the established rules of crystal structure (see 'Chemistry's lone heroes').

Yet Shechtman was not the first to spot evidence of the crystals. "Given the relative simplicity of making these materials, it is certain that they would have been seen by numerous scientists before, who dismissed them because they didn't fit the rigid rules of crystallography," says Veit Elser, a physicist at
Cornell University in Ithaca, New York. Indeed, in 1979, Marc van Sande, a 27-yearold doctoral student working in the Electron Microscopy for Materials Science (EMAT) group at the University of Antwerp, Belgium, had recorded electron diffraction patterns from metal alloys that showed clear evidence of quasicrystals. Close to the end of his $\mathrm{PhD}$, van Sande just filed the confusing patterns in the EMAT library: he was keen to take up his new job with the Belgian materials-technology company Umicore, where he is now an executive vice-president.

"We were making so many new discoveries every week with the high-resolution electron microscopes that the more awkward things were set aside," recalls van Sande. "I'm realistic about it: seeing the pattern is a long way from investigating it and publishing it."

Shechtman, unaware of van Sande's work, observed similar odd diffraction patterns about three years later - and grasped their importance. He had the self-belief to plough on with his work, despite the scorn of luminaries such as chemist and two-time Nobel prizewinner Linus Pauling. "If you have repeated your observations and are sure you are correct, then listen to others but don't give up because people tell you 'this cannot be,," Shechtman told Nature.

Thirty years ago, scientists were taught that all crystalline materials were composed of atoms packed into regularly repeating threedimensional lattices, such as the hexagonal honeycomb of a beehive. This definition dictated that the lattice must have basic repeating units with particular symmetries: these units could be rotated by one-half, onequarter or one-sixth of a full circle and still look the same. Pentagonal symmetry was ruled out, because no perfectly regular lattice could exhibit it.

On 8 April 1982, Shechtman, who was on sabbatical at the US National Bureau of Standards (now the National Institute of Standards and Technology, NIST) in Gaithersburg, Maryland, found that an artificial alloy of aluminium and manganese disobeyed the rules.

When he shot electrons through the material, they created a regular diffraction pattern, apparently proving that the material's atomic structure consisted of orderly repeating elements. But that pattern showed a forbidden symmetry - it could be rotated by both onetenth and one-fifth of a full circle and would still look the same. In his laboratory notebook, Shechtman wrote: "10 Fold???"

Others did their best to persuade him that his discovery was wrong. "People didn't believe me," he says, adding that his dogged pursuit of the problem even led his group director to suggest he move to another team. Shechtman finally got his findings published in November 1984, along with Ilan Blech, a materials scientist at Technion; John Cahn, a physicist at NIST; and Denis Gratias, a crystallographer then at the Centre for Metallurgic Chemistry in Vitry, France (D. Shechtman et al. Phys. Rev. Lett. 53, 1951-1953; 1984).

By chance, mathematicians Paul Steinhardt and Dov Levine - both then at the University of Pennsylvania in Philadelphia - were at the same time completing a rigorous theory

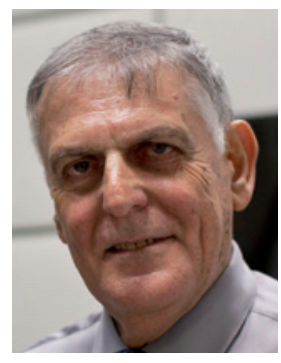

"People didn't believe me." Dan Shechtman of the three-dimensional version of mathematical curios known as Penrose tilings, structures with an apparent five-fold symmetry that were created by British mathematician Roger Penrose in the 1970s. Steinhardt coined the term 'quasicrystals' for the resulting structures: neither classically 
- periodic crystals, nor a glass-like mess of disordered atoms. They were what Shechtman had seen in his metallic alloy.

Other examples soon flooded in from around the globe. In 2009, Steinhardt and other researchers reported the first quasicrystal structure to be seen in a natural material: an alloy of aluminium, copper and iron reported to have come from 200-millionyear-old rocks in Russia’s Koryak Mountains (L. Bindi et al. Science 324, 1306-1309; 2009).

It still isn't clear how atoms assemble into quasicrystal structures, and the discovery has found few real-world applications. However, quasicrystals do have potential: they are very hard, are poor at conducting heat and electricity, and have non-stick surfaces. But Shechtman's key contribution to chemistry lies in opening scientists' eyes to the possibility of new forms of matter, notes Sven Lidin, an inorganic chemist at Stockholm University and a member of the Nobel Committee for Chemistry. As Lidin wrote in his description of the award: "The discovery of quasicrystals has taught us humility." -

\section{CHEMISTRY'S LONE HEROES}

How many prizewinners does it take...
Dan Shechtman got the chemistry Nobel prize all to himself this year something that has happened in $61 \%$ of all chemistry Nobels, but only in $45 \%$ of Nobels in physics and $37 \%$ in medicine. As large teams and international scientific collaborations come to dominate research, the Royal Swedish Academy of Sciences is likely to find itself bumping up against the rule that the Nobel prize can be awarded to no more than three people in any one discipline - and the strain is already evident (see chart). Since 2000, the three scientific Nobels have been won by the maximum possible number of nine researchers on five occasions.
| Chemistry I Physics I Medicine

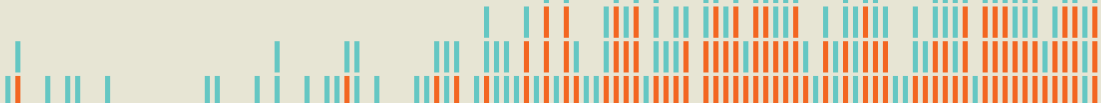
|| || || || || || ||||| | ||||| ||||||||||||||||||||| ||||||||||||||||||||||||||||||||||||

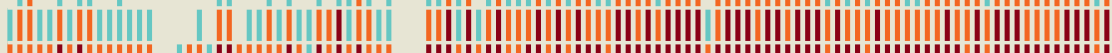


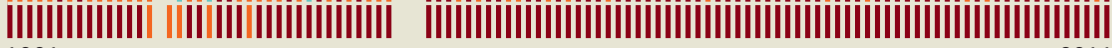
1901

\section{BY ERIC HAND}

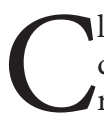
lose and bright though it is, the Sun still defies a thorough understanding. One reason is that some of the features on its roiling surface are too small and short-lived to be studied even by the world's largest solar telescopes.

That will change if the US National Solar Observatory (NSO) proceeds with its latest project - the Advanced Technology Solar Telescope (ATST), a Sun-gazing behemoth due to be built on the summit of Haleakala, the highest peak on the Hawaiian island of Maui. This month, an officially appointed arbiter will weigh the scientists' goals against objections raised by conservationists and Native Hawaiian groups to decide whether the US\$298-million project can break ground later this year.

With more than twice the aperture of existing solar telescopes (see 'Eyes on the Sun'), the 4-metre ATST will be large enough to tease out small structures on the Sun, particularly magnetic flux tubes - the hitherto unseen precursors to sunspots. Sunspots, in turn, give rise to giant coronal loops and flares, which can unleash bursts of radiation and cause magnetic disturbances that sometimes threaten spacecraft, communication networks and power grids.

Heliophysicists say the improved resolution should help solar science to move into the challenging terrain of predicting space weather. "The societal need is really driving this community," says Thomas Zurbuchen, a solar physicist at the University of Michigan in Ann Arbor, who is vice-chair of a decadal survey for heliophysics that is due to release its research priorities next March.

Although not the only phenomenon the ATST

\section{"Societal need is really driving this community."} will explore, flux tubes are of especial interest because these short-lived, 100-kilometre-scale features are thought to be conduits of magnetic field lines through the solar surface. Studying them as they evolve should shed light on larger-scale solar phenomena that can affect Earth. "If you want to understand coronal heating and solar-wind acceleration, then you have to understand these fundamental scales," says Todd Hoeksema, a solar physicist at Stanford University in California.

Ultimately, solar astronomers hope to monitor the Sun 24 hours a day using a global network of telescopes. A European telescope of similar size is planned for the Canary Islands, and India is considering a 2-metre instrument. But the ATST will be built first if it passes a final hurdle.

Last December, more than seven years after the NSO chose the site, Hawaii's Board of Land and Natural Resources gave permission to develop it. A group called Kilakila O Haleakala ('Majestic is Haleakala' in Hawaiian) has contested the decision. An endangered seabird, the Hawaiian petrel or 'ua'u (Pterodroma sandwichensis), nests near the proposed site. Furthermore, some Native Hawaiians say that the telescope's stark white enclosure - necessary to control heat-induced air currents within the scope's optical path - will scar a sacred area. But the telescope builders say they will do all they can to mitigate the impacts. Construction 